\title{
Research on the Cultivation and Promotion of College Students' Legal Quality and Legal Knowledge Based on Deep Learning
}

\author{
Cheng Cheng, ${ }^{1}$ Wenlin Chen $\mathbb{D}^{2},{ }^{2}$ and $\mathrm{Ao}^{\mathrm{Li}^{3}}$ \\ ${ }^{1}$ School of Natural Resources and Surveying, Nanning Normal University, Nanning 530001, China \\ ${ }^{2}$ China-ASEAN Technology Transfer Center, Nanning 530007, China \\ ${ }^{3}$ School of Law, Wuhan University, Wuhan 430072, China
}

Correspondence should be addressed to Wenlin Chen; 20130292@stu.nmu.edu.cn

Received 1 August 2021; Accepted 26 August 2021; Published 22 September 2021

Academic Editor: Zhihan Lv

Copyright (c) 2021 Cheng Cheng et al. This is an open access article distributed under the Creative Commons Attribution License, which permits unrestricted use, distribution, and reproduction in any medium, provided the original work is properly cited.

Under the new situation, it is urgent to strengthen the cultivation of the legal consciousness of young college students, which makes the research on the cultivation and promotion of college students' legal quality and legal knowledge become very important. This article is aimed at studying the cultivation and promotion of college students' legal quality and legal knowledge based on deep learning. This article first analyzes the legal quality and legal knowledge level of college students by proposing a questionnaire survey method, interview method, and interdisciplinary research method and establishes an explanatory structure model of the factors affecting the legal quality of college students; secondly, it introduces the basic theories of deep learning and explains its practical application; finally, the training rules of neural network are constructed through experiments, and the stage method of legal quality training based on BP neural network is introduced in detail. Considering that virtual reality technology has recently penetrated into the game industry and other fields, we have reason to believe that it will find ways to enter the legal knowledge training industry. The experimental results of this article show that the cultivation and improvement of college students' legal quality and legal knowledge based on deep learning can reduce the momentary confusion and impulsiveness of college students. Among them, more than $80 \%$ of college students who know a little about the Constitution account for more than $80 \%$, which also shows the importance of cultivating and improving the laws and regulations of college students. The results show that the method is accurate and fast.

\section{Introduction}

1.1. Background. Since the end of the 1980s, China has begun to spread the law on a large scale nationwide. It has been 31 years since the 15th National Congress of the Communist Party of China in 1997. It clearly established the establishment of a socialist country under the rule of law. The 17th National Congress of the Communist Party of China proposed to "fully implement the principle of governing the country by law, and accelerate the construction of a socialist country ruled by law." The 18th National Congress of the Communist Party of China in 2012 further emphasized the comprehensive promotion of the rule of law, brought the rule of law to a new height, and cultivated and strengthened the law. Awareness is the key to urging our country to achieve the goal of "a country under the rule of law" as soon as possible and has a very important impact on building a socialist country under the rule of law with Chinese characteristics. The use of big data and Internet of Things technology makes it easier to use real-time data. In fact, artificial intelligence technology has made a lot of progress in the legal industry. A big man in the field of artificial intelligence recalled, "When I spoke during an event in Europe a few years ago, I already noticed that artificial intelligence technology will play a greater role in the legal industry. The remarks laughed loudly. However, this view has become deeply ingrained now." Therefore, under the new situation, it is extremely urgent to strengthen the cultivation of the legal consciousness of young college students. This is not only the demand for comprehensively improving quality education but also the demand for improving the legal literacy of the whole people and establishing a comprehensive society under the rule of law. Based on the comprehensive rule of law, this 
article conducts an in-depth discussion on how to improve the current legal awareness of college students in higher education. It points out that the specific path should be accurately positioned, the purpose is clear, and the cultivation of college students' legal awareness will be scientifically constructed. The mechanism allows college students to comprehend the application of legal consciousness in real life and cultivates a sound legal consciousness of college students by means of "moisturizing things silently" and hopes that they will use rational thinking when facing temptation to conform to social development The required choice is towards the development direction of individual healthy growth.

1.2. Significance. The improvement of college students' legal awareness is the basic guarantee for realizing the basic strategy of ruling the country by law. The strength of contemporary college students' legal awareness and ideological and moral quality directly affect the realization of the effect of comprehensively governing the country according to law and to a certain extent reflect the progress of our country's rule of law civilization. In the process of building the rule of law in our country, individuals in society are the subjects of the rule of law, and at the same time, they are also the most vivid and important factor in the process of realizing the rule of law. Whether it is legislation, law enforcement, justice, or law-abiding, their status is the state of activities of social people. Behavior is the ultimate goal. Ideological and political education in colleges and universities is an important channel for the development of legal education for college students. However, current college students frequently commit cases of violation of morals and ethics and violations of laws and regulations. There are differences between the ideal and reality and goals and status quo in the cultivation of college legal awareness. The cultivation of legal consciousness of college students lies in shaping the legal world outlook, but the formation of a scientific and reasonable legal world outlook often depends on the improvement of the rule of law environment. It is not difficult to find that a good legal environment is an effective way to improve and improve the legal consciousness of college students.ECOFlT uses artificial intelligence technology. In this case, by combining machine learning functions and algorithms, operators can detect the use patterns of equipment; in this way, managers in the legal industry can readjust and arrange equipment to better meet the needs of lawyers for learning. This article is aimed at discussing how to improve the cultivation of legal consciousness and puts forward effective and practical suggestions for it. It has important theoretical significance for further improving the ideological and political quality of college students and cultivating high-quality college students with both ability and political integrity.

1.3. Related Work. The loss of legal quality has caused the phenomenon of college students' illegal crimes to become more and more serious, and it has become a common issue in the quality education of colleges and universities. Pedrini pointed out that the economic literature has widely acknowledged the increasingly important role of corporate training in the knowledge economy. Training can increase labor productivity, enhance competitiveness, and enhance the company's innovation capabilities. However, this key role of training raises questions about the optimal level of corresponding investment. In fact, the company that bears training costs may not be able to make full use of the relevant benefits. In addition, training may promote structural changes and stimulate nationwide growth. Therefore, for efficiency reasons, it is reasonable to justify the existence of voluntary or mandatory legal and/or institutional tools aimed at solving suboptimal investments in human capital development. The purpose of this research is to systematically classify the main legal and institutional means that can solve the potential inefficiency of training investment, but the legal meaning of employees within the enterprise is not strong enough and needs to be strengthened through training [1]. Winkelmann proposed background techology, social media, and access to health care continue to grow simultaneously. There is limited research on sports training students' knowledge of the ethical and legal practices of using technology and social media to protect health information. The objective was to explore the use of social media by sports training students and to determine their understanding of patient privacy regulations in social media and technology. Online survey tools and knowledge assessment are designed and set up. There are 652 sports training students in total from patients or other participants. The intervention is within the scope of the clinical experience of sports training students, and based on the control and use of patient privacy compliance in health care, knowledge evaluation of 12 items is carried out. The main outcome indicators developed a tool consisting of 26 questions, including 14 demographic information and 12 knowledge items, and the content was verified by a Delphi expert panel of sports training, health care information technology, and risk management lawyers [2]. Suhova analyzed the effectiveness of testing methods in student legal education and revealed the specific impact of testing technology on the activation of educational potential in distance education and the development of knowledge control skills in student legal education in different courses. The report analyzed the complexity of examination technology, pointed out the importance of this method in the process of higher education, revealed the structure and form of examination, and proposed the possible application of this method in law education. In addition, the report also reveals the specific impact of using examinations to check the quality of legal knowledge to improve the understanding of first-year students, especially foreign students, of complex and large amounts of legal materials [3]. The test method as a knowledge verification complex is studied.

\subsection{The Main Content and Innovations of This Paper}

1.4.1. Research Content. The interview method is used to briefly summarize the connotation of deep learning in the network environment [4] and its characteristics and other related content. It analyzes the internal mechanism of deep learning college students' legal quality and legal knowledge 
cultivation and promotion from two aspects: the theoretical learning and the realization process of deep learning. Through the form of a questionnaire survey, we understand the current status of college students' legal quality and legal knowledge training and learning and clarify the problems existing in the process of college students' deep learning of legal knowledge under the network environment [5]. It is discussed how teachers can support college students in deep learning based on deep learning theory and use the proposed strategies. Virtual reality technology is used to improve scholars' knowledge of law.

1.4.2. Innovation Points. At present, there are few research algorithms for the cultivation and promotion of legal quality and legal knowledge of college students based on deep learning in China. This article studies the feasibility of deep learning methods in the cultivation and promotion of legal quality and legal knowledge. Using distributed technology [6, 7], a cloud computing and big data platform is built based on deep learning-based legal quality and legal knowledge cultivation and promotion analysis [8] to solve the problem of massive big data storage and computing performance [9]], to provide a good research platform for the cultivation and research of legal knowledge based on big data in the future. There are few studies on the process of deep learning at home and abroad. Based on previous studies, this article attempts to build a process model for the cultivation and promotion of legal knowledge from the cognitive process of college students. Systematic research is based on deep learning to discuss the cultivation and promotion of college students' legal quality and legal knowledge. At present, the research results on the deep learning of college students in the deep learning theoretical environment are quite rich. However, from the perspective of teachers, there are relatively few researches supporting deep learning of college students. Therefore, this paper studies college students' in-depth study of law under the network environment.From the perspective of teachers, measures to promote deep learning of college students are proposed.

\section{Training Methods and Theories}

\subsection{Research Methods for the Cultivation of College Students' Legal Quality}

2.1.1. Questionnaire Survey Method. In order to grasp the real situation of college students' legal quality, this research will issue questionnaires to some undergraduate college students in five famous domestic universities.

2.1.2. Interview Method. This research also takes the interview method as one of the important research methods and uses the semistructured interview method to interview some college students and college teachers, in order to deepen the grasp of the status quo of college students' legal quality and the status quo of college legal publicity work [10], for college students. Research on the path to improve legal quality provides ideas.

2.1.3. Interdisciplinary Research Method. Interdisciplinary research methods refer to the use of multidisciplinary theo- ries, methods, or results to integrate a research topic into a whole. With the help of system structure modeling technology [11], an explanatory structure model of the influencing factors of college students' legal quality has been established, which realizes the hierarchical, scientific, and intuitive nature of college students' legal quality; in addition, when analyzing the basic quality of college students, it is necessary to use sociology descriptive statistical analysis methods in research.

2.2. Related Theories of Deep Learning. Through interdisciplinary research, it is found that although deep learning has a late start in the education field, some researchers have conducted in-depth research in combination with some theories related to deep learning, such as interaction theory [12] and distributed cognitive theory. For the research content and research design, Bloom's educational goal classification theory, situational cognition theory, and metacognition theory are selected as the theoretical basis of this research.

2.2.1. Bloom's Education Objective Classification Theory. In Bloom's teaching theory system [13], according to the classification of educational goals, the field of learning cognition is divided into six levels: knowledge, understanding, application, analysis, evaluation, and creation. The cognitive level of deep learning corresponds to the last four higher levels of cognition, focusing on problem solving and knowledge evaluation creation. Therefore, combined with the connotation and characteristics of deep learning, deep learning is mainly based on the application, analysis, evaluation, and creation of knowledge.

2.2.2. Situational Cognition Theory. Situational cognition theory is a kind of learning that can provide meaningful learning, and the construction of learning based on real situations and practice community that it advocates provides important conditions for the occurrence of deep learning. The occurrence of deep learning behaviors can also be regarded as actions based on context to a certain extent. For example, deep learning involves problem solving, and the problem to be faced is a complex problem about the real situation. New knowledge is built on the basis of experience and transferred to new situations [14].

2.2.3. Metacognition Theory. Metacognition is cognitive cognition, self-awareness, self-monitoring, and self-regulation of cognitive activities (such as self-learning and thinking), which are the result of highly developed self-awareness. As shown in Table 1, it can be seen that metacognitive knowledge emphasizes the learner's mastery of subject knowledge and the transfer and application of knowledge. Metacognitive experience $[15,16]$ emphasizes that learners can connect theory with practice and demonstrate in actual situations. Metacognitive monitoring emphasizes that learners should learn to learn, be able to formulate corresponding learning plans, and conduct self-monitoring during the implementation process. When completing tasks and solving problems, they can change problem-solving methods and strategies and reflect on them. 
TABle 1: The embodiment of metacognition in deep learning.

\begin{tabular}{lc}
\hline Metacognition & Deep learning \\
\hline $\begin{array}{l}\text { Metacognitive } \\
\text { knowledge }\end{array}$ & Requires learners not only to master knowledge but also to understand the process of knowledge generation \\
$\begin{array}{l}\text { Metacognitive } \\
\text { experience }\end{array}$ & The learner is required to be able to critically check the logic of the argument, and the learner is required to evaluate \\
$\begin{array}{l}\text { Metacognitive } \\
\text { monitoring }\end{array}$ & new ideas and to be able to link these ideas with conclusions \\
\end{tabular}

\section{Experiments Based on Deep Learning}

3.1. Training Rules of Neural Networks in Deep Learning. The neural network BP algorithm [17] training mechanism can be divided into two different methods: updating according to the data model and updating according to batches and blocks. If you train directly according to the data model, the model will change due to changes in weights. This makes it unreliable to improve it into a parallelized BP algorithm technology based on data model allocation and mapping [18]. The training method of updating according to batches and blocks is to update the weights after accumulating multiple model changes. This is conducive to applying the algorithm to multiprocessors [19] for parallelized calculations. The training results trained by the training mechanism under the above two different methods may be different.

For the sample-based training mechanism, the training mechanism must constantly adjust the error generated during the sample calculation process, which is very similar to the "greedy algorithm" in the algorithm [20], although it is kept as much as possible in each calculation. It is optimal, but as the number of training continues to accumulate, the error adjustment of the training algorithm will greatly affect the speed of convergence. The so-called greedy choice property means that the overall optimal solution of the problem sought can be selected through a series of local optimal choices. In other words, when considering which choice to make, we only consider the best choice for the current problem without considering the result of the subproblem. The calculation method of batch and block processing is to adjust the weight after the calculation of the error of multiple samples is completed, so that the error is adjusted from the overall perspective, which is beneficial to speed up the convergence and also reduces the error.

Through the above comparison, we can know that when there are many samples; the changes in multiple weights are calculated and then adjusted. Compared with the adjustment of individual weights, it is a fairly effective neural network training with faster convergence speed. Many mature learning networks have been proposed for this batch and block processing training method, such as deep ensemble learning networks, block processing Boltzmann machines [21], and deep belief networks. Therefore, this topic uses batch and block update training methods to train the network. First, the formula for calculating the error of the model-based training method is as follows:

$$
E=\frac{L}{2}(D-O)^{2}=\frac{L}{2} \sum_{k=1}^{\mathrm{i}}\left(d_{k}-o_{k}\right)^{2} \text {. }
$$

Among them, $O$ is the actual output and $D$ is the expected output.

An iterative gradient descent algorithm based on the model-based training method can be divided into the following three steps:

(1) First, set L to $\Delta W^{(L)}=0$ (all zero matrix)

(2) Then loop through all the samples, adjust the weight of each sample, that is, solve the partial derivative $\Delta J(W, x, y)$, get $\delta_{K}(L+1), \delta_{j}(L)=f($. $\sum_{k=1}^{n_{L}+1} w_{j k} \delta_{k}(L+L), j=1,2, \cdots, n_{L}$

(3) Calculate the weights with the results obtained after solving

$$
W_{i j}^{(L)}:=W_{i j}^{(L)}+\eta \delta_{j}(L+1) Y_{i}(L)
$$

The calculation error formula for the training method based on batch and block update is shown in the following formula:

$$
E_{\min }=\frac{1}{2} \sum_{P=1}^{P} \sum_{k=1}^{i}\left(d_{k}^{p}-o_{k}^{p}\right)^{2}
$$

Among them, $D$ is the expected output, $O$ is the actual output, and $P$ is the total number of samples.

The gradient descent algorithm based on batch and block update training algorithms can be divided into the following three steps:

(1) Consistent with the algorithm based on model processing, first set $L$ to $\Delta W^{L}=0$

(2) Then traverse the entire sample, use the error formula to solve the partial derivative $\Delta_{w(L)} J(W, x, y)$, $\delta_{k}(L+1), \delta_{j}(L)=f(.) \sum_{k=1}^{n_{L+1}} w_{j k} \delta_{k}(L+L), j=1,2, \cdots$, $n_{L}$ and realize the addition of the adjusted values, as shown in the following formula: 


$$
\Delta W_{i j}{ }^{L}=\Delta W_{i j}{ }^{L}+\eta \delta_{j}(L+1) Y_{i}(L) .
$$

And update the weight according to the result, as shown in the following formula:

$$
W_{i j}{ }^{L}:=W_{i j}{ }^{L}+\eta \delta_{j}(L+1) Y_{i}(L) .
$$

Last, update the ownership value

$$
W_{i j}{ }^{L}:=W_{i j}{ }^{L}+\alpha\left[\frac{1}{m} \Delta W_{i j}{ }^{L}\right] .
$$

3.2. Staging Algorithm of Legal Quality Training Based on BP Neural Network. This section will introduce the staging method of legal quality training based on the BP neural network. It is mainly divided into four stages: signal preprocessing, feature extraction, network training, and effect evaluation.

The BP neural network can be approximated as a continuous nonlinear system. A typical three-layer BP neural network is shown in Figure 1.

BPNN needs to be trained to obtain the ability of memory and prediction before it can make predictions. BPNN refers to the process of neuron activation and transmission that imitates human beings. Training can be divided into the following steps.

Step 1. Initialization of the network. First determine the number of nodes in the input layer $n$, the number of nodes in the hidden layer, and the number of nodes in the output layer, $m$.

According to the input and output sequence $(X, Y)$, the weights between each layer are initialized. Finally, the learning rate and neuron activation function are determined.

Step 2. Calculate the hidden layer output $H$ according to the input vector $X$, the weight $w_{i j}$ of each node of the input layer and the hidden layer, and the offset vector $a$. The details are as follows:

$$
H=f\left[\sum_{i=1}^{n} w_{i j} x_{i}-a_{i}\right], \quad j=1,2, \cdots L .
$$

Among them, $l$ is the number of hidden layer nodes and $f$ is the activation function of hidden layer neurons. There are many types of this activation function.

Step 3. Calculate the prediction output vector $O$ of the hidden layer according to the output vector $H$ of the hidden layer, the connection weight $w_{j k}$, and the offset vector $b$, as follows:

$$
Q_{k}=\sum_{j=1}^{L} H_{j} w_{j k}-b_{k}, \quad k=1,2, \cdots, m .
$$

Step 4. According to the expected output $Y$ and the predicted output vector $O$, calculate the prediction error of the network as follows:

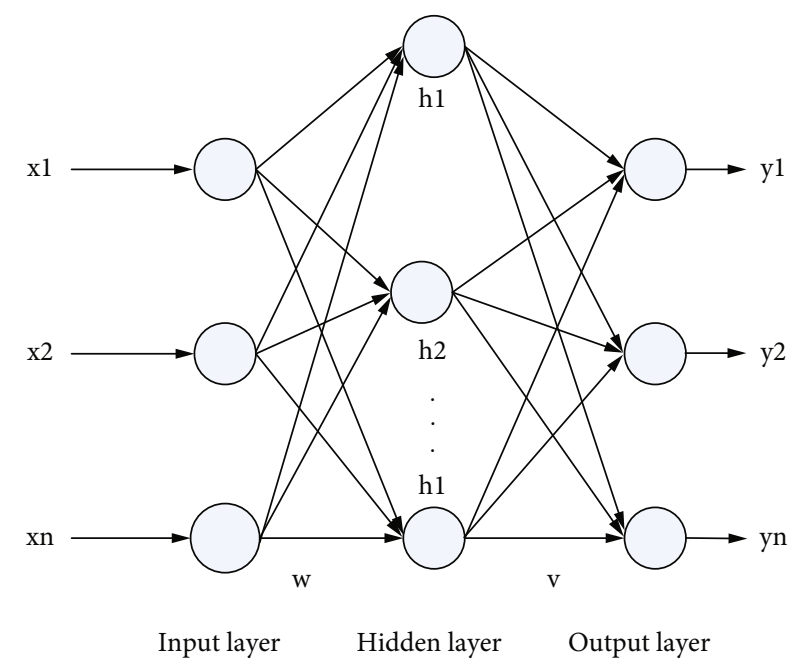

FIgURE 1: Three-layer BP neural network.

$$
e_{\mathrm{k}}=Y_{k}-O_{k}, \quad k=1,2, \cdots, m \text {. }
$$

Step 5. Update the weights $W_{j k}$ and $W_{i j}$ of the neural network according to the prediction error. The details are as follows:

$$
W_{i j}=W_{i j}+\eta H_{j}\left(1-H_{j}\right) \mathrm{x}(i) \sum_{k=1}^{m} W_{j k} e_{k},
$$

where $i=1,2 \cdots, n ; \quad j=1,2, \cdots L ; \quad W_{j k}=W_{j k}+\eta H_{j} e_{k}$ $j=1,2, \cdots L ; k=1,2, \cdots, m$, and $\eta$ is the learning rate.

Step 6. According to the prediction error, we update the partial vectors $a$ and $b$ of the network nodes. The details are as follows:

$$
\begin{aligned}
& \mathrm{a}_{\mathrm{j}}=a_{j}+\eta H_{j}\left(1-H_{j}\right) \sum_{k=1}^{m} W_{j k} e_{k}, \quad j=1,2, \cdots, m, L, \\
& \mathrm{~b}_{\mathrm{k}}=b_{k}+e_{k}, \quad k=1,2, \cdots, m .
\end{aligned}
$$

Entropy is a quantitative parameter used to measure the uncertainty of signal output, as follows:

$$
\mathrm{EN}=\sum_{\mathrm{j}=1}^{N}\left(x^{2}{ }_{i j}\right) \log \left(x^{2}{ }_{i j}\right), \quad 1 \leq n \leq 3840,1 \leq i \leq 5 .
$$

\section{Investigation and Analysis of the Status of Contemporary College Students' Legal Quality}

\subsection{Survey Objects and Sample Distribution}

4.1.1. Survey Object. In order to better understand the legal quality of college students, the author designed a questionnaire from the aspects of legal knowledge and the concept of the rule of law and conducted a questionnaire survey on 
TABLE 2: Questionnaire on legal qualities of college students.

\begin{tabular}{lcccccccc}
\hline \multirow{2}{*}{ Category } & \multicolumn{2}{c}{ Gender } & \multicolumn{2}{c}{ Grade } & \multicolumn{2}{c}{ Profession } \\
Men & Women & One & Two & Three & Four & Science and technology & Humanities & Total \\
\hline Number of people & 147 & 125 & 85 & 92 & 72 & 23 & 168 & 99 \\
Percentage (\%) & 55 & 48 & 32.1 & 35.1 & 27.5 & 8.5 & 67 & 38 \\
\hline
\end{tabular}

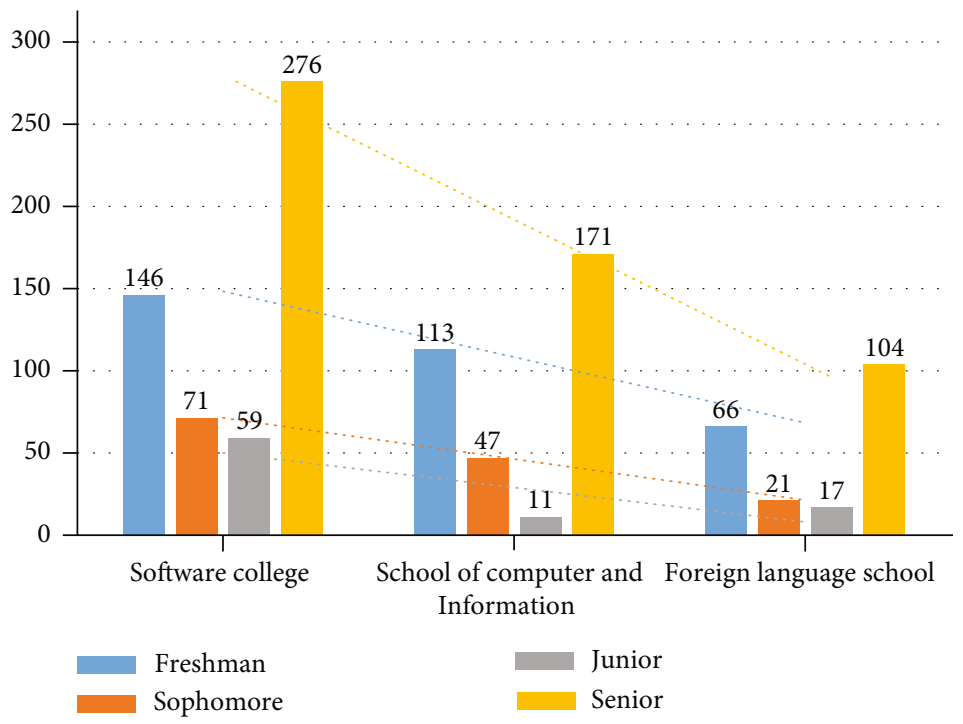

Figure 2: Sample distribution of three colleges.

the undergraduates of a domestic university. This survey is expected to issue 300 questionnaires; half of them are men and women, with same majors, grades, and educational qualifications. 265 questionnaires were effectively returned, with an effective recovery rate of $88 \%$. See Table 2 for details.

4.1.2. Sample Distribution. In this paper, a random sampling survey of 608 college students from three colleges was conducted, and a total of 551 valid questionnaires were returned, with an effective recovery rate of $90.63 \%$. This article mainly distributes the scale to first-year students in colleges and universities, and second- and third-year students distribute a small amount of questionnaires as auxiliary data. The sample distribution is shown in Figure 2.

4.2. Investigation and Analysis of College Students' Legal Knowledge. The survey of college students' legal knowledge mainly focuses on understanding the status of college students' mastery of legal knowledge from the level of understanding of the Constitution, basic laws, and related professional legal knowledge, as shown in Table 3.

Survey data shows that $2 \%$ of college students know the Constitution very well, $11 \%$ of college students know the Constitution well, $80 \%$ of college students know a little bit about it, and 7\% do not know anything about it. College students can understand and learn all kinds of legal knowledge and master the most basic legal knowledge through a variety of ways and means such as classrooms, books, the Internet, and the media. [22] Some college students have a better understanding of our country's Constitution. But in general, college students still know very little about the Constitution, think the Constitution has little to do with them, and have no interest in the Constitution.

In the question of "which type of law do you like to study," $85 \%$ of college students emphasized the understanding of practical law, only $1 \%$ of college students focused on theoretical law, and $3 \%$ of college students had no interest in law. This shows that under the influence of multiple values and pragmatism, college students have insufficient knowledge of law.

As a group of contemporary college students with a relatively high level of knowledge and cultural level, they are the main force in the cause of socialist modernization. They must not only be proficient in their own majors but also have their own professional legal knowledge as a guarantee, so as to adapt to the society and solve for themselves in the future. In the survey with their professional legal knowledge, $20 \%$ of college students understand it better, and $80 \%$ of college students do not know it well. It can be seen that some college students are aware of the importance of professional legal knowledge and can take the initiative to learn and understand, but the vast majority of students only focus on the learning of professional knowledge and ignore the learning of legal knowledge related to their own majors, which leads to college students' insufficient understanding of their professional legal knowledge.

4.3. Investigation and Analysis of College Students' Concept of the Rule of Law. In the investigation of college students' concept of the rule of law, it is mainly to understand the rule of law of college students from the aspects of the relationship 
TABLE 3: The status of college students mastering legal knowledge.

\begin{tabular}{lcccc}
\hline Problem & \multicolumn{4}{c}{ Options and percentages } \\
\hline Your knowledge of the Constitution & Know it well & Better understanding & A little bit & Do not understand at all \\
& $2 \%$ & $11 \%$ & $80 \%$ & $7 \%$ \\
Which type of law do you like & Theoretical law & Practical law & Like both & Not interested \\
Your knowledge of the relevant & $1 \%$ & $82 \%$ & $11 \%$ & $6 \%$ \\
laws of the major you are studying & Know it well & Better understanding & A little bit & Do not understand at all \\
\hline
\end{tabular}

TABLE 4: Will it violate the rule of law concept of traffic rules.

\begin{tabular}{|c|c|c|c|c|}
\hline \multirow{3}{*}{$\begin{array}{l}\text { Problem } \\
\text { What do you think of the } \\
\text { relationship between the } \\
\text { law and yourself }\end{array}$} & \multicolumn{4}{|c|}{ Options and percentages } \\
\hline & $\begin{array}{l}\text { As long as you do not break the law, you } \\
\text { have nothing to do with yourself }\end{array}$ & $\begin{array}{l}\text { Always related } \\
\text { to yourself }\end{array}$ & Somewhat related & $\begin{array}{c}\text { Cannot say it } \\
\text { clearly }\end{array}$ \\
\hline & $6 \%$ & $22 \%$ & $7 \%$ & $65 \%$ \\
\hline \multirow{2}{*}{$\begin{array}{l}\text { What will you do when your } \\
\text { legal rights are violated }\end{array}$} & Solve privately & $\begin{array}{l}\text { Seek legal } \\
\text { protection }\end{array}$ & Tolerate & $\begin{array}{l}\text { Depends on } \\
\text { the situation }\end{array}$ \\
\hline & $1 \%$ & $82 \%$ & $11 \%$ & $6 \%$ \\
\hline \multirow[t]{2}{*}{ Will you break the traffic rules } & Do & Sometimes & $\begin{array}{l}\text { Someone violates the rules } \\
\text { and does not comply }\end{array}$ & Will not \\
\hline & 0 & $19 \%$ & $38 \%$ & $43 \%$ \\
\hline
\end{tabular}

between the law and themselves, how to deal with their own rights and interests, and whether they will violate traffic rules [23]. For the status of concept, as shown in Table 4.

In the question of "what do you think of the relationship between law and yourself," $63 \%$ of college students believe that law is closely related to their own interests and realize that law is closely related to people's lives, but $37 \%$ of college students think that the relationship is not very relevant and that they have little to do with the law, especially the understanding of the essential characteristics of law. When their legal rights and interests are violated, $66 \%$ of college students choose to depend on the situation, $23 \%$ of college students seek legal means to protect their legal rights, $7 \%$ of them take what they can tolerate, and $6 \%$ of college students said that they would seek the person in private. The above results indicate that college students have a weak concept of the rule of law as a whole. The specific manifestation is that most students are skeptical of the law, and when their legal rights are violated, they did not think about or were unwilling to use the law to protect their rights and did not believe in the law. The corresponding is some college students would rather adopt the method of being tolerant and solving this problem in private. It is the duty of every citizen to obey the traffic rules. The survey shows that $43 \%$ of college students will consciously abide by the traffic rules, $29 \%$ of college students do not abide by the traffic rules, and $28 \%$ of college students think that if someone violates the rules, they will not abide by the traffic rules. As a highknowledge group, college students should have high ideological and moral qualities and legal qualities. The survey shows that more than half of college students do not obey the traffic rules well. Some of them take a wait-and-see attitude and will not obey the traffic rules if someone breaks the rules.
Another part of college students directly violated the traffic rules and did not abide by the traffic rules.

\subsection{Status Quo of Deep Learning for College Students}

4.4.1. Learning Interest. When investigating whether college students are interested in learning, 12 people think they are very interested, accounting for $7 \%$ of the total; 54 people are more interested, accounting for $30 \%$ of the total; 88 of them are relatively uninterested, accounting for $41 \%$ of the total number; 30 people who are not interested at all, accounting for $17 \%$ of the total number; and less clear accounts for $8 \%$ of the total. It can be seen that the current college students' interest in learning is not high, and we should adopt some effective ways to cultivate college students' interest in learning, as shown in Figure 3.

4.4.2. The Learning Process. When investigating whether college students are skeptical about the knowledge of books and the content of university teachers or professors, only $2 \%$ of college students often doubt it, $45 \%$ of students are occasionally skeptical, and $56 \%$ of college students have never doubted, as shown in Figure 4.

Only a very small number of college students have a strong skepticism, and most students are still in passive learning. It is extremely important to cultivate a critical skepticism in college students.

4.4.3. Relative Lack of Knowledge of Legal Theory. In the survey, it is found that college students are more inclined to laws that will have useful value [24], such as the latest civil code. When asked which aspect of the law you want to learn, 50 people chose economic law, accounting for $17.4 \%$ of the surveyed people, and 93 people chose civil and commercial 


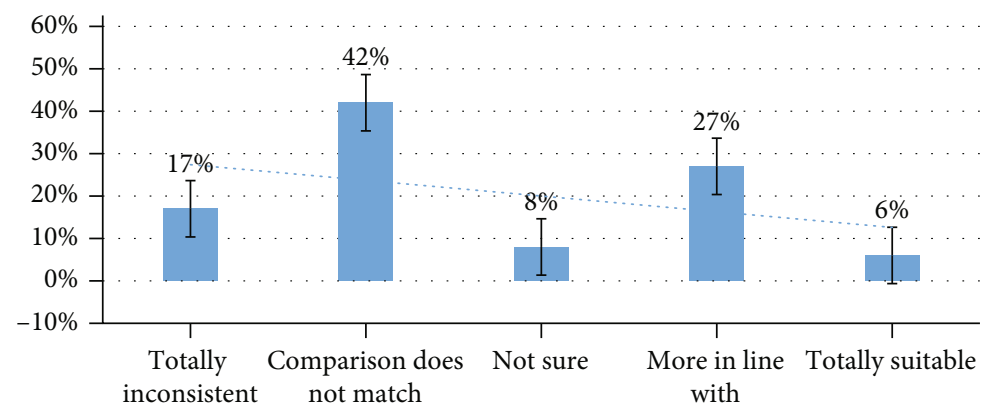

Figure 3: College students' interest in learning.

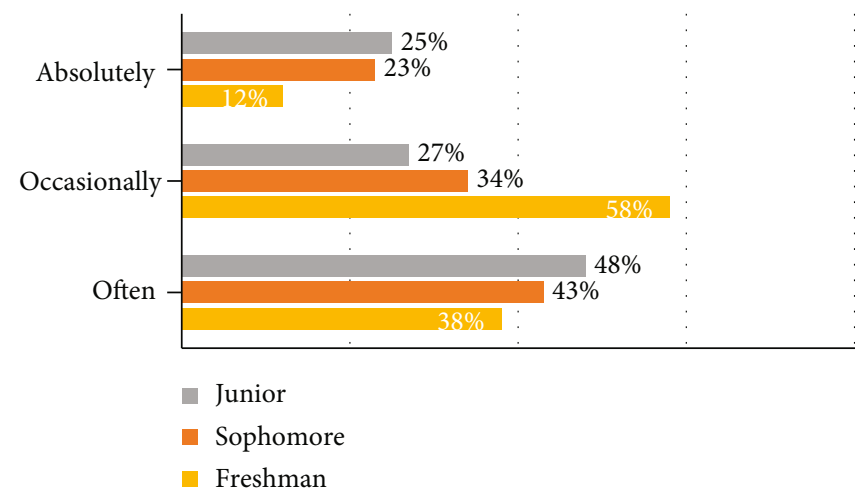

Figure 4: The connection between new and old knowledge when college students are studying.

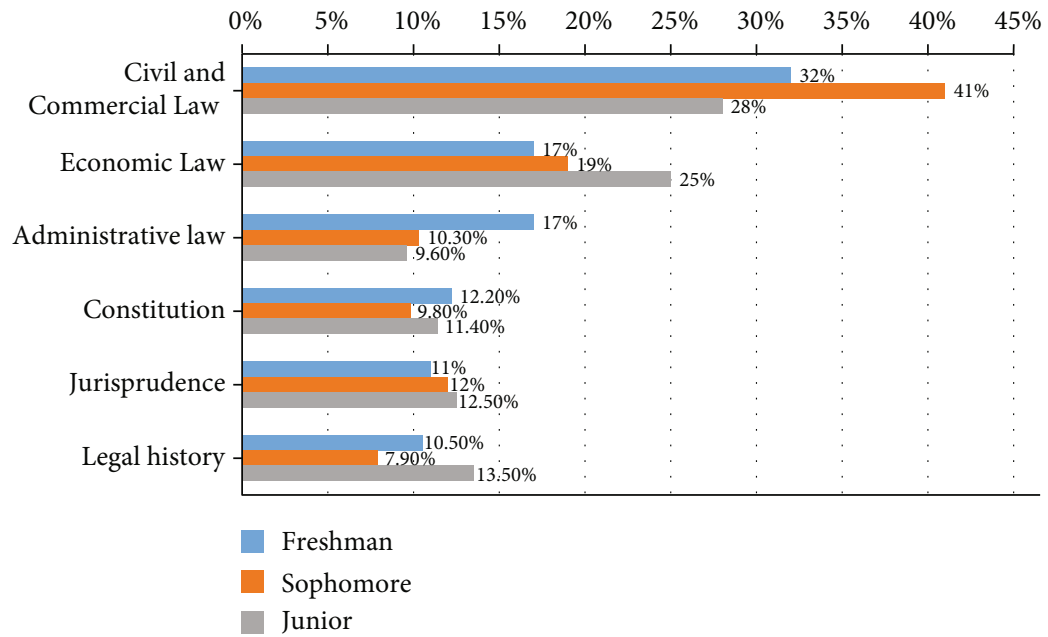

FIGURE 5: Selection of legal theory knowledge.

law, accounting for $32.4 \%$ of the surveyed people. The number of people who chose administrative law was 48 , accounting for $16.7 \%$ of the surveyed people; the number of people who chose the Constitution was 35, accounting for $12.2 \%$ of the surveyed people; and the number of people who chose the legal history was 31 , accounting for $10.8 \%$ of the surveyed people. The number of jurisprudence is 30 , accounting for $10.5 \%$ of the number of people investigated. Theoretical knowledge is the foundation of legal knowledge. If the basic knowledge is not in place, it is difficult to make correct judg- ments and take reasonable measures when encountering major legal practices in specific work. Therefore, college students are interested in practical law, but are not interested in relatively abstract legal knowledge, which is unfavorable to the formation of college students' legal knowledge systematization, as shown in Figure 5.

4.4.4. Weak Usage Ability. To achieve the goal of ruling the country according to law in our country [25], citizens are not only required to abide by the law, but more importantly, 


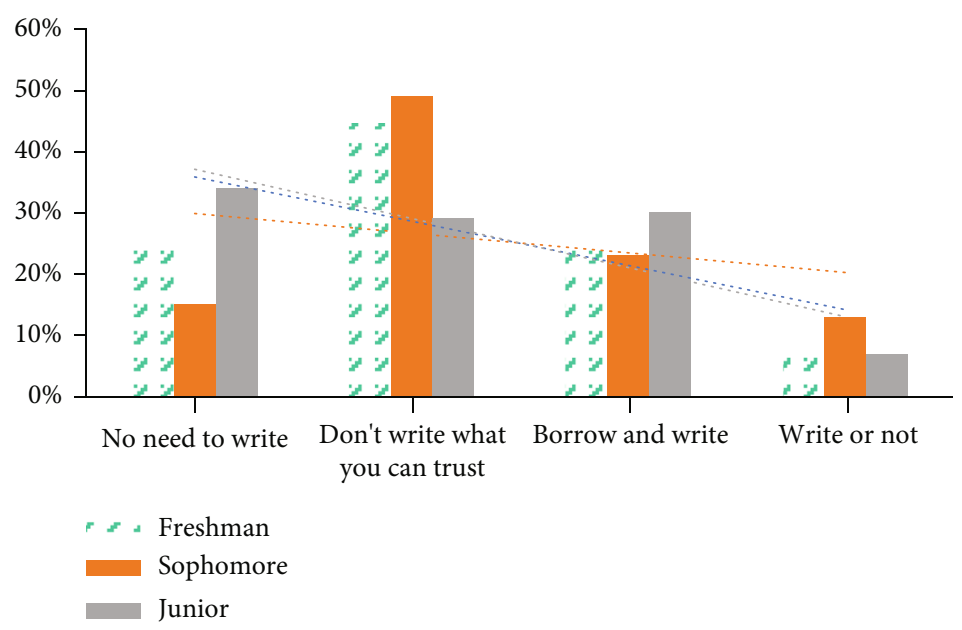

FIGURE 6: Views on writing IOUs from relatives and friends borrowing money.

they must learn how to use the law on the basis of abiding by the law. According to the survey (see Figure 6), college students are weak in how to use it. When asked the question, "do you think relatives and friends do not need to write an IOU for borrowing money?", some college students choose not to write it, some college students choose not to write if they are trustworthy, some college students choose to borrow more and write more, and some college students choose not to write. You can choose to write or not. Accordingly, we must more comprehensively enhance the legal consciousness and usage ability of college students.

\section{Conclusions}

At present, the quality and legalization of college students have the opportunity to be recognized by law enforcement agencies. Undergraduates who understand that colleges and universities have good laws can better explore the development of physical and mental health. In order to protect themselves, they have taken out legal weapons to prevent and protect college students from crimes and increase their sense of security. It is just that the students of the law school can work together and study together to increase their legal consciousness, strengthen their legal consciousness, combat laws and crimes, and implement the country's great strategy with the law. On the basis of research, this article hopes to attract the attention of relevant departments, which has important guiding significance for improving the legal consciousness and comprehensive quality of college students. As a system based on artificial intelligence, the legal knowledge training program developed by the Aktiv Virtual System shows good adaptability in terms of exercise time, preference, and training intensity. In other words, the more information a program that monitors users obtains, the more guidance and suggestions it can provide. The Aktiv Virtual System has also been updated with the first generation of technology, so that it can better capture the user's learning in real time. As a special social group, college students are the backbone of socialist construction in the new era and new environment. In the socialist rule of law environment, it is necessary to improve the socialist democratic rule of law system; create a good social environment; optimize radio, television, and network channels; and strengthen the legal awareness of each family in order to have a positive impact on college students. Institutions of higher learning should attach importance to the legal education of college students in order to improve their legal awareness, establish correct legal concepts, promote the consciousness of college students to act in accordance with the law, strengthen the legal quality of college students, and enable them to use legal weapons to actively stop crimes, maintaining and promoting social stability and harmony.

\section{Data Availability}

We did not obtain analytical permission from the data provider because of trade confidentiality.

\section{Conflicts of Interest}

The authors declared that they have no conflicts of interest to this work.

\section{Acknowledgments}

This study was supported by the "Research on the Construction Mode of New Engineering of Surveying and Mapping Geographic Information Specialty under the Intelligent Era" (New Engineering Research and Practice Project of Nanning Normal University) and "Exploration and Practice of Artificial Intelligence + Course Construction for Postgraduates Majoring in Surveying, Mapping and Geographic Information in Local Colleges and Universities under the Background of the New Engineering Era" (JGY2020121).

\section{References}

[1] G. Pedrini, "Law and economics of training: a taxonomy of the main legal and institutional tools addressing suboptimal investments in human capital development," European Journal of Law and Economics, vol. 43, no. 1, pp. 83-105, 2017. 
[2] Z. K. Winkelmann, E. R. Neil, and L. E. Eberman, "Athletic training students' knowledge of ethical and legal practice with technology and social media," Athletic Training Education Journal, vol. 13, no. 1, pp. 3-11, 2018.

[3] M. Hu, Y. Zhong, S. Xie, H. Lv, and Z. Lv, "Fuzzy system based medical image processing for brain disease prediction," Frontiers in Neuroscience, vol. 15, no. 965, 2021.

[4] X. Hao, G. Zhang, and S. Ma, “Deep learning," International Journal of Semantic Computing, vol. 10, no. 3, pp. 417-439, 2016.

[5] G. Litjens, T. Kooi, B. E. Bejnordi et al., "A survey on deep learning in medical image analysis," Medical Image Analysis, vol. 42, no. 9, pp. 60-88, 2017.

[6] S. Levine, P. Pastor, A. Krizhevsky, J. Ibarz, and D. Quillen, "Learning hand-eye coordination for robotic grasping with deep learning and large-scale data collection," International Journal of Robotics Research, vol. 37, no. 4-5, pp. 421-436, 2018.

[7] T. O'Shea and J. Hoydis, "An introduction to deep learning for the physical layer," IEEE Transactions on Cognitive Communications \& Networking, vol. 3, no. 4, pp. 563-575, 2017.

[8] J. Lee, "Integration of digital twin and deep learning in cyberphysical systems: towards smart manufacturing," vol. 38 , no. 8 , pp. 901-910, 2020.

[9] K. Reiss, K. Footman, V. Akora, W. Liambila, and T. D. Ngo, "Pharmacy workers' knowledge and provision of medication for termination of pregnancy in Kenya," The Journal of Family Planning and Reproductive Health Care, vol. 42, no. 3, pp. 208212, 2016.

[10] S. Heide, R. Lessig, V. Hachmann et al., "Establishment of two forensic medicine OSCE stations on the subject of external post-mortem examination," International Journal of Legal Medicine, vol. 132, no. 1, pp. 311-319, 2018.

[11] T. Melnyk and I. Dobroskok, "Training of the future vocational education teachers in the conditions of student-centred learning and teaching," Professional Education Methodology Theory and Technologies, vol. 10, no. 10, pp. 143-157, 2019.

[12] D. Z. Bo, "Maintaining the correct guidance of public opinion promoting social harmony in tibetan-inhabited area," Nationalities Research in Qinghai, 2010.

[13] R. Carabez and M. Scott, "'Nurses don't deal with these issues': nurses' role in advance care planning for lesbian, gay, bisexual and transgender patients," Journal of Clinical Nursing, vol. 25, no. 23-24, pp. 3707-3715, 2016.

[14] X. Zhang, B. He, and T. Luo, "Training query filtering for semi-supervised learning to rank with pseudo labels," World Wide Web, vol. 19, no. 5, pp. 833-864, 2016.

[15] G. Jovanic and V. Petrovic, "The needs, practice and effectiveness of education and professional training of convicts," Specijalna Edukacija i Rehabilitacija, vol. 16, no. 2, pp. 199-221, 2017.

[16] H. Qian and P. Youngs, "The effect of teacher education programs on future elementary mathematics teachers' knowledge: a five-country analysis using TEDS-M data," Journal of Mathematics Teacher Education, vol. 19, no. 4, pp. 371-396, 2016.

[17] X. Wang, L. Gao, S. Mao, and S. Pandey, "CSI-based fingerprinting for indoor localization: a deep learning approach," IEEE Transactions on Vehicular Technology, vol. 66, no. 1, pp. 1-776, 2016.

[18] M. Oriakhi, C. Sealy, A. Adenote, O. Alabi, and M. Ahluwalia, "Improving residents' skills and confidence on advance direc- tive discussion: a quality improvement project," Journal of Community Hospital Internal Medicine Perspectives, vol. 9, no. 5, pp. 419-421, 2019.

[19] D. J. Norris, "Comparing language and literacy environments in two types of infant-toddler child care centers," Early Childhood Education Journal, vol. 45, no. 1, pp. 95-101, 2017.

[20] D. Ravi, C. Wong, F. Deligianni et al., "Deep learning for health informatics," IEEE Journal of Biomedical and Health Informatics, vol. 21, no. 1, pp. 4-21, 2017.

[21] D. Marmanis, M. Datcu, T. Esch, and U. Stilla, "Deep learning earth observation classification using ImageNet pretrained networks," IEEE Geoscience and Remote Sensing Letters, vol. 13, no. 1, pp. 105-109, 2016.

[22] B. Youngerman, B. E. Zacharia, Z. L. Hickman, J. N. Bruce, R. A. Solomon, and D. L. Benzil, "Making milestones: development and implementation of a formal socioeconomic curriculum in a neurosurgical residency training program," Neurosurgery, vol. 79, no. 3, pp. 492-498, 2016.

[23] S. Albarqouni, C. Baur, F. Achilles, V. Belagiannis, S. Demirci, and N. Navab, "AggNet: deep learning from crowds for mitosis detection in breast cancer histology images," IEEE Transactions on Medical Imaging, vol. 35, no. 5, pp. 1313-1321, 2016.

[24] S. Demirçin, A. Tütüncüler, F. Aslan, S. Velipaşaoğlu Güney, M. Atılgan, and H. Gülkesen, "The knowledge level and opinions of physicians about the medical and legal procedures related to physical child abuse," Balkan Medical Journal, vol. 34, no. 2, pp. 140-146, 2017.

[25] W. Zhao and S. Du, "Spectral-spatial feature extraction for hyperspectral image classification: a dimension reduction and deep learning approach," IEEE Transactions on Geoscience and Remote Sensing, vol. 54, no. 8, pp. 4544-4554, 2016. 